\title{
Tumorigenic lung tumorospheres exhibit stem-like features with significantly increased expression of CD133 and ABCG2
}

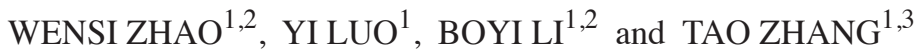 \\ ${ }^{1}$ Department of Oncology, The First Affiliated Hospital of Chongqing Medical University; \\ ${ }^{2}$ Chongqing Key Laboratory of Molecular Oncology and Epigenetics; ${ }^{3}$ Radiology \& Oncology Laboratory, \\ Chongqing Medical University, Chongqing 400016, P.R. China
}

Received August 5, 2015; Accepted June 29, 2016

DOI: $10.3892 / \mathrm{mmr} .2016 .5524$

\begin{abstract}
Accumulating evidence supports the existence of cancer stem cells (CSCs) in human tumors, and the successful certification of CSCs may lead to the identification of therapeutic targets, which are more effective for the treatment of cancer. The use of spherical cancer models has increased in popularity in cancer stem cell investigations. Tumorospheres, which are used as a model of CSCs and are established in serum-free medium supplemented with growth factors under non-adherent conditions, are one of the most commonly used cancer spherical models and are a valuable method for enriching the CSC fraction. To investigate whether this model is applicable in lung cancer (LC), the identification of lung CSCs and their capacities is essential. In the present study, lung CSCs were enriched by sphere-forming culturing and their stem-like properties were assessed. The results indicated that the lung tumorospheres had enhanced proliferation, clonality, invasion and cisplatin-resistance, and showed significantly increased expression levels of CD133 and breast cancer resistance protein (ABCG2). These results, together with findings previously reported in literature, indicated that the sphere-forming culturing of LC cells induced the enrichment of CSCs and that the tumorospheres exhibited stem cell characteristics. In addition, the higher expression levels of CD133 and ABCG2 in the tumorospheres may provide a rationale for therapeutic targets for $\mathrm{LC}$.
\end{abstract}

Correspondence to: Dr Tao Zhang, Department of Oncology, The First Affiliated Hospital of Chongqing Medical University, 1 Youyi Road, Yuzhong, Chongqing 400016, P.R. China

E-mail: tumorzzt@163.com

Abbreviations: CSCs, cancer stem cells; TICs, tumor initiating cells; SP, side population; LC, lung cancer; ABCG2/BCRP, breast cancer resistance protein; FITC, fluorescein isothiocyanate; FACS, fluorescence activated cell sorting; PI, propidium iodide; H\&E, hematoxylin and eosin

Key words: cancer stem cells, tumorospheres, lung cancer, CD133, breast cancer resistance protein, tumorigenicity

\section{Introduction}

Lung cancer (LC) is the leading cause of cancer-associated mortality worldwide. Despite continuous efforts to improve therapeutic outcomes, the overall 5-year survival rate remains $<16 \%(1,2)$. The definite mechanism leading to the metastasis and relapse of primary tumors remains to be elucidated; however, the cancer stem cell (CSC) hypothesis states that a subpopulation of tumor cells with distinct stem-like properties is responsible for tumor initiation, differentiation, possibly distant metastasis and resistance to conventional chemoradiotherapy. Members of this subpopulation are defined as CSCs or tumor-initiating cells (TICs) (3).

The isolation and identification of CSCs is an essential premise. Currently, CSCs are isolated primarily using four methods: Detection of CSC-specific biomarkers by flow cytometry, assessment of side population (SP) phenotypes by Hoechst 33342 excretion, floating sphere culturing in serum-free conditions and determination of aldehyde dehydrogenase (ALDH) activity (4). None of the methods mentioned above are exclusively used to isolate CSCs. Previously, tumorsphere models have been widely described and used in investigations of cancer (5). Increasing evidence has indicated that the serum-free sphere culture protocol is a reasonable approach to enrich CSCs in vitro, including neurospheres from glioblastoma $(6,7)$.

Simultaneously, several studies have supported the existence of CSCs in LC, and lung CSCs with enhanced tumorigenicity have been reported as a subset of cells, which exclude Hoechst 33342 dye (SP phenotype), including drug-resistant, CD133+, $\mathrm{ALDH}^{\text {high }}$ and $\mathrm{CD}_{4} 4^{+}(8)$. Although no universal marker or set of markers has been fully established for lung CSCs, studies have identified lung CSCs by the detection of $\mathrm{CD}_{133^{+}}$, SP phenotype $\left(\mathrm{ABCG}^{+}\right)$and/or ALDH ${ }^{\text {high }}(9,10)$.

CD133 is a transmembrane glycoprotein; this protein was initially described as a specific marker of human hematopoietic stem cells, and has been used as the primary marker of putative CSCs (11). Various types of solid malignant tumor that express CD133 have been reported to have aggressive biological behavior, poor prognosis and high rates of recurrence (12-17). Breast cancer resistance protein (ABCG2), is a multidrug resistance efflux pump and maintains the SP phenotype based on its excretion of Hoechst 33342. The 
overexpression of ABCG2 is associated with resistance to a wide range of anticancer agents $(18,19)$. ABCG2 has also been reported as a potential marker of TICs (20). To date, CD133 and ABCG2 appear to be the most reproducible markers of lung CSCs.

The present study attempted to generate lung CSCs using a sphere-forming assay, and to analyze the features of lung tumorospheres to examine the correlation between the expression levels of two primary candidate CSC markers, CD133 and ABCG2. The experimental results suggested that the stem-like properties were enriched in the lung tumorospheres, with high expression levels of CD133 and ABCG2. Although the present study did not demonstrate that all the sphere-derived cells were CSCs, the results suggested that $\mathrm{CD} 133^{+}$and $\mathrm{ABCG} 2^{+}$ cells may be a small subpopulation, which contributes to the determination of stem-like features in lung tumorospheres.

\section{Materials and methods}

Reagents. Mouse monoclonal antibody against ABCG2 BXP-21 (cat. no. ab3380) was purchased from Abcam (Cambridge, MA, USA). Allophycocyanin (APC)-conjugated anti-CD133/1 (cat. no. 130-090-826) antibody and rabbit anti-CD133 (cat. no. MAB4399) antibody were obtained from Miltenyi Biotec (Bergisch Gladbach, Germany) and EMD Millipore (Billerica, MA, USA), respectively. Rabbit monoclonal antibody directed against $\beta$-actin (cat. no. 4970) and horseradish-peroxidase-conjugated horse anti-rabbit and anti-mouse (cat. nos. 7074 and 7076) IgG secondary antibodies were purchased from Cell Signalling Technology,Inc.(Danvers, MA, USA). Fluorescein isothiocyanate (FITC)-conjugated goat anti-mouse IgG antibody (cat. no. \#E031210-01) was purchased from EarthOx, LLC (San Francisco, CA, USA). Alexa Fluor ${ }^{\circledR}$ 568-conjugated goat anti-rabbit IgG antibody (cat. no. \#A-11011) was purchased from Invitrogen; Thermo Fisher Scientific, Inc. (Waltham, MA, USA). Reverse transcription (RT) and quantitative polymerase chain reaction (qPCR) kits were purchased from Takara Biotechnology Co., Ltd. (Dalian, China). Cisplatin was obtained from Sigma-Aldrich (St. Louis, MO, USA), and dissolved in a $0.15 \mathrm{M} \mathrm{NaCl}$ solution. Aliquots were stored at $-20^{\circ} \mathrm{C}$ for up to 3 months and thawed immediately prior to use. All other chemicals and solvents were of the highest analytical grade available.

Cell culture. The A549 human LC cell line was obtained from American Type Culture Collection (Rockville, MD, USA) and cultured in RPMI-1640 medium (Hyclone; GE Healthcare Life Sciences, Logan, UT, USA) supplemented with $10 \%$ fetal bovine serum (FBS; Gibco; Thermo Fisher Scientific, Inc.) and $1 \%$ penicillin/streptomycin at an atmosphere of $5 \% \mathrm{CO}_{2}$ at $37^{\circ} \mathrm{C}$. Cells in the logarithmic phase of growth were used for all experiments.

LC tumorosphere culture, harvest and differentiation. Suspended cells were collected from confluent A549 cells and centrifuged at $800 \mathrm{x}$ g for $5 \mathrm{~min}$ at room temperature. The pellets were gently dissociated with a pipette and resuspended in serum-free Dulbecco's modified Eagle's medium (DMEM)-F12 medium (Gibco; Thermo Fisher Scientific, Inc.). The cells were plated at a density of $1 \times 10^{3}$ cells $/ \mathrm{ml}$ in ultra-low attachment plates (Corning Inc. Acton, MA, USA) supplemented with $20 \mathrm{ng} / \mathrm{ml}$ basic fibroblast growth factor (bFGF; PeproTech, Inc., Rocky Hill, NJ, USA), 20 ng/ml epidermal growth factor (PeproTech, Inc.) and 2\% B27 (Gibco; Thermo Fisher Scientific, Inc.) in a $5 \% \mathrm{CO}_{2}$ humidified incubator at $37^{\circ} \mathrm{C}$. The medium was replaced every 2-3 days by carefully removing half the upper layer of medium and replacing it with an equal volume of fresh medium. It has been reported that the more serial passages in the spheres, the more CSCs present (4). The spheres were collected by gentle centrifugation at $600 \mathrm{x}$ g for $6 \mathrm{~min}$ at room temperature, and mechanically dissociated into single cell suspensions until they were of a sufficient number (>200 cells) for passaging. The third passage of LC spheres was used in the present study to ensure the reliability of the results. The spheres were filtered using a cell strainer, and those with a diameter $>40 \mu \mathrm{m}$ were selected for use in the subsequent experiments. To determine the serum-induced differentiation of sphere-forming cells, spheroids were isolated and cultured in DMEM supplemented with $10 \% \mathrm{FBS}$ without growth factors at $37^{\circ} \mathrm{C}$ in a $5 \% \mathrm{CO}_{2}$ humidified incubator.

RT-PCR and qPCR analyses. The total RNA of the A549 attached cells and corresponding spheres were extracted using TRIzol reagent (Invitrogen; Thermo Fisher Scientific, Inc.). First-strand cDNA was synthesized from $1 \mu \mathrm{g}$ total RNA using M-MuLV Reverse Transcriptase (Applied Biosystems, Foster City, CA, USA) to a final volume of $20 \mu \mathrm{l}$. For RT-PCR, samples were assayed in a $12.5 \mu \mathrm{l}$ reaction mixture containing $2.5 \mu \mathrm{l}$ cDNA, $1.25 \mu \mathrm{l}$ of 10X Ex Taq Buffer, $1 \mu \mathrm{l} \mathrm{dNTP}$ mixture, $1 \mu \mathrm{l}$ forward primer, $1 \mu \mathrm{l}$ reverse primer, $0.05 \mu \mathrm{l}$ TaKaRa Ex Tag HS and $5.7 \mu \mathrm{l}$ RNase Free $\mathrm{dH}_{2} \mathrm{O}$. The RT reaction was performed using a DNA Engine Peltier Thermal Cycler (Bio-Rad Laboratories, Inc., Hercules, CA, USA). The semi-quantitative PCR conditions were as follows: Initial denaturation at $95^{\circ} \mathrm{C}$ for $2 \mathrm{~min}$, followed by 32 cycles of denaturation at $94^{\circ} \mathrm{C}$ for $30 \mathrm{sec}$, annealing at $55^{\circ} \mathrm{C}$ for $30 \mathrm{sec}$, and extension at $72^{\circ} \mathrm{C}$ for $30 \mathrm{sec}$, with extension at $72^{\circ} \mathrm{C}$ for $3 \mathrm{~min}$ in the final cycle. For qPCR, samples were assayed in a $10 \mu 1$ reaction mixture containing $5 \mu \mathrm{l}$ of $2 \mathrm{X}$ One Step SYBR RT-PCR Buffer, $0.45 \mu \mathrm{l}$ of PrimeScript 1 Step Enzyme mix, $0.4 \mu \mathrm{l}$ PCR forward primer $(10 \mu \mathrm{M}), 0.4 \mu \mathrm{l}$ PCR reverse primer $(10 \mu \mathrm{M})$, $2 \mu \mathrm{l}$ cDNA and $1.8 \mu \mathrm{l}$ RNase Free $\mathrm{dH}_{2} \mathrm{O}$ using the One-Step SYBR $^{\circledR}$ PrimeScript $^{\mathrm{TM}}$ qPCR kit (Takara Biotechnology Co., Ltd.). The qPCR was performed using an ABI 7500 Real-Time PCR system (Applied Biosystems) for a total of 40 cycles with an annealing temperature of $95^{\circ} \mathrm{C}$ for $5 \mathrm{sec}$ and $60^{\circ} \mathrm{C}$ for $20 \mathrm{sec}$. The primer pairs encoding products of 113, 69, 126, 281, 206 and $225 \mathrm{bp}$, respectively, were as follows: CD133, forward 5'-GAGTCGGAAACTGGCAGATAGCA-3' and reverse 5'-ACGCCTTGTCCTTGGTAGTGTTG-3'; ABCG2, forward 5'-CACAAGGAAACACCAATGGCT-3' and reverse 5'-ACA GCTCCTTCAGTAAATGCCTTC-3'; octamer-binding transcription factor 4 (OCT4), forward 5'-ACATCAAAGCTC TGCAGAAAGAAC-3' and reverse 5'-CTGAATACCTTC CCAAATAGAACCC-3'; Nanog, forward 5'-AGAAGGCCT CAGCACCTA-3' and reverse 5'-GGCCTGATTGTTCCA GGATT-3'; sex-determining region Y-box 2 (Sox2), forward 5'-AGCAACGGCAGCTACAGCA-3' and reverse 5'-TGG GAGGAAGAGGTAACCACAG-3' and GAPDH, forward 
5'-GAAGGTGAAGGTCGGAGTC-3' and reverse 5'-GAA GATGGTGATGGGATTTC-3'. All primers were synthesized by BGI Tech Solutions Co., Ltd. (Beijing, China). The thermal cycling conditions were as follows: $95^{\circ} \mathrm{C}$ for $30 \mathrm{sec}$, followed by $5 \mathrm{sec}$ at $95^{\circ} \mathrm{C}$, and $1 \mathrm{~min}$ at $60^{\circ} \mathrm{C}$ for 40 cycles. Gene expression was normalized to GAPDH, and the fold change was calculated using the following formula: Fold change in gene expression $=2^{-(\Delta \Delta \mathrm{dCq})}(21)$.

Flow cytometric analysis of the expression levels of CD133 and $A B C G 2$. In total, $1.0 \times 10^{6}$ viable attached cells and sphere-forming cells were collected. The cells were wasHed twice in phosphate-buffered saline (PBS), following which they were incubated with mouse monoclonal anti-ABCG2 (1:200 dilution) for $10 \mathrm{~min}$ at $4^{\circ} \mathrm{C}$ and then incubated with FITC-conjugated goat anti-mouse IgG (1:200 dilution) for another $10 \mathrm{~min}$ at $4^{\circ} \mathrm{C}$ in the dark. Subsequently, the cells were washed in PBS, resuspended, fixed in $100 \mu 11 \%(\mathrm{~m} / \mathrm{v})$ paraformaldehyde and subjected to fluorescence analysis using flow cytometry. Dead cells were eliminated using $1 \mathrm{mg} / \mathrm{ml}$ propidium iodide (PI) staining (Sigma-Aldrich). To detect the expression of $\mathrm{CD133}$, the cells were incubated with anti-CD133-APC for $15 \mathrm{~min}$ at $4^{\circ} \mathrm{C}$ in the dark, and subsequent procedures were performed, according to the protocol described above. The data were processed using CellQuest software (BD Biosciences, San Jose, CA, USA).

Immunofluorescence staining. The A549 attached cells and sphere-forming cells were seeded on glass coverslips in at a density of $5.0 \times 10^{3}$ cells/well six-well plates, and cultured in a $5 \% \mathrm{CO}_{2}$ incubator at $37^{\circ} \mathrm{C}$ overnight. The cells were fixed by immersion in ice-cold methanol for $15 \mathrm{~min}$. Following washing of the coverslips twice in PBS and blocking for $30 \mathrm{~min}$ in blocking buffer (10\% normal goat serum and $0.5 \%$ Triton X-100 in PBS), the coverslips were incubated with mouse anti-ABCG 2 and rabbit anti-CD133 primary antibodies at a 1:200 dilution for $12 \mathrm{~h}$ at $4^{\circ} \mathrm{C}$. The coverslips were then washed three times in PBS for 5 min each and incubated with FITC-conjugated goat anti-mouse IgG or Alexa Fluor ${ }^{\circledR}$ 568-conjugated goat anti-rabbit IgG secondary antibody at a 1:200 dilution for $30 \mathrm{~min}$ at $37^{\circ} \mathrm{C}$. Subsequently, the cells were counterstained with 4',6-diamidino-2-phenylindole and visualized using an inverted fluorescence microscope (Leica, Mannheim, Germany).

Cell viability analysis. The A549 adherent cells and sphere-derived cells were plated in triplicate at a density of 4,000 cells/well in standard coated 96-well plates and allowed to adhere overnight at $37^{\circ} \mathrm{C}$ in a $5 \% \mathrm{CO}_{2}$ humidified incubator. Wells containing medium only were used as a background negative control. Cell proliferation was measured during the following 4 days using a Cell Counting Kit-8 (CCK-8; Dojindo Laboratories, Kumamoto, Japan), according to the manufacturer's protocol. The spectrometric absorbance was measured at $450 \mathrm{~nm}$ using a microplate reader. The growth curves were constructed according to the mean value of absorbance relative to the background. To examine drug sensitivity, the cells were first seeded in a 96-well plate at a density of 5,000 cells/well and cultured in medium containing increasing concentrations of cisplatin $(0-25.6 \mu \mathrm{g} / \mathrm{ml})$ for $48 \mathrm{~h}$ at $37^{\circ} \mathrm{C}$ in a
$5 \% \mathrm{CO}_{2}$ humidified incubator. At the end of the drug exposure duration, cell viability was measured using the CCK-8 assay, and the growth inhibition rate and the half maximal inhibitory concentration $\left(\mathrm{IC}_{50}\right)$ values were calculated using GraphPad Prism 5.0 software (GraphPad Software, Inc., La Jolla, CA, USA).

Cell invasion analysis. Cell invasion assays were performed using 24-well Transwell plates ( $8 \mu \mathrm{m}$ pore size; Corning, Inc.) coated with $1 \mathrm{mg} / \mathrm{ml}$ Matrigel (BD Biosciences). In total, $1.0 \times 10^{5}$ cells/well were suspended in $300 \mu 10.1 \%$ bovine serum albumin (Invitrogen; Thermo Fisher Scientific, Inc.)/serum-free medium and added to the upper compartment of the Transwell plates. Subsequently, $500 \mu 1$ complete medium containing $10 \%$ FBS was added to the lower wells of each plate, and the cells were incubated in a $5 \% \mathrm{CO}_{2}$ incubator for $24 \mathrm{~h}$ at $37^{\circ} \mathrm{C}$. After $24 \mathrm{~h}$, the upper surface of the chambers were scraped using cotton swabs, and the cells on the lower surface of the membrane were considered invasive cells. These invasive cells were fixed for $15 \mathrm{~min}$ in methanol, stained with Giemsa solution and examined using a TE2000 inverted microscope (Nikon, Tokyo, Japan).

Cell cycle analysis. For cell cycle analysis, the adherent A549 cells, spheres and sphere-forming cells following serum-induced culture were harvested by trypsinization and fixed with ice-cold $70 \%$ ethanol overnight at $4^{\circ} \mathrm{C}$. The cells were then washed twice in PBS, resuspended in PBS and stained with PI/RNase staining buffer (BD Biosciences) at $37^{\circ} \mathrm{C}$ for $30 \mathrm{~min}$. The cell cycle profiles were obtained using flow cytometry at $488 \mathrm{~nm}$, and the data were analyzed using CellQuest software (BD Biosciences).

Western blot analysis. Cell lysates of A549 attached cells and spheres were prepared according to manufacturer's details of the protein extract kit (KEYGEN Biotech, Beijing, China). Protein concentrations were determined using the bicinchoninic acid method. Equal quantities of protein $(50 \mu \mathrm{g} /$ lane of total extract) were separated by $12 \%$ sodium dodecyl sulphate-polyacrylamide gel electrophoresis and then electrophoretically transferred onto PVDF membranes (Bio-Rad Laboratories, Inc.). The membranes were blocked in 5\% skim milk powder dissolved in Tris-buffered saline with Tween 20 (TBST) for $2 \mathrm{~h}$ at room temperature, following which they were incubated with the following primary antibodies at $4^{\circ} \mathrm{C}$ overnight: ABCG2, CD133 and $\beta$-actin. The membranes were then washed three times in TBST buffer, and were subsequently incubated with secondary antibody for $1.5 \mathrm{~h}$ at room temperature. The bands were visualized using a molecular imaging system. Densitometric analysis was performed using Image-ProPlus software (Media Cybernetics, Inc., Rockville MD, USA), and $\beta$-actin was used as a control.

Tumorigenicity experiments. Male $(n=20)$ and female $(n=200$ athymic BALB/c nude mice (4-6 weeks old) with body weights of 18-22 $\mathrm{g}$ were provided by the Experimental Animal Centre of Chongqing Medical University (Chongqing, China). All mice were housed in microinsolator cages in a specific homothermic pathogen-free environment with a 12-h light/dark cycle and access to food and water ad libitum. To generate 
A
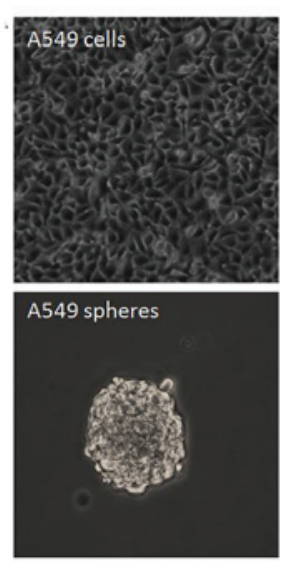
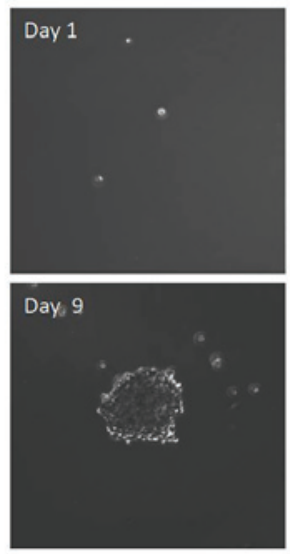
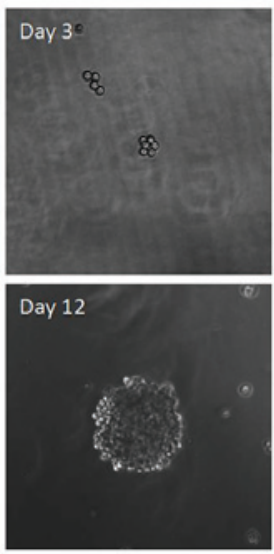

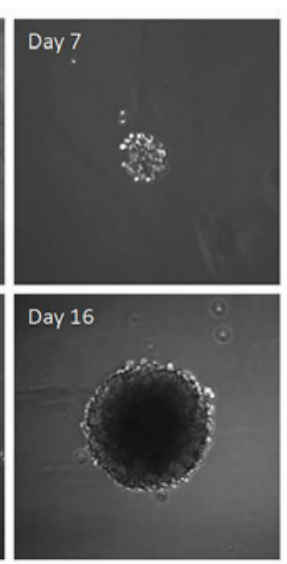

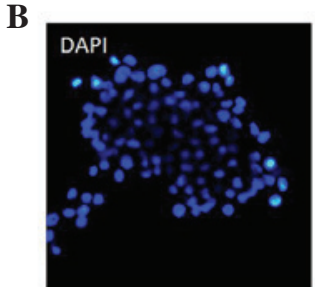

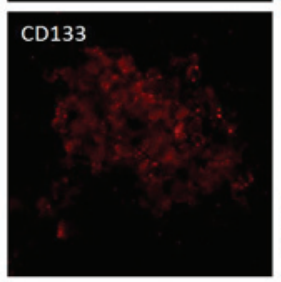

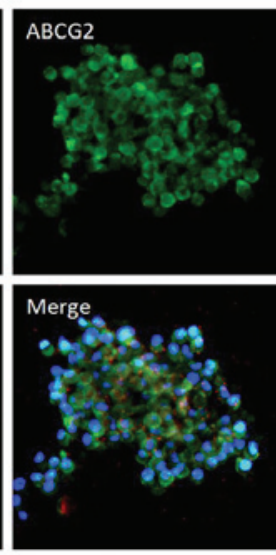

Figure 1. Phase images of sphere-forming assay in A549 cells. (A) Growth of a single cell was recorded separately on days 1, 3, 7, 9, 12 and 16 (original magnification, x100). (B) Intracellular localization of CD133 and ABCG2. Immunostaining showed upregulation of CD133 and ABCG2 in the lung cancer spheres (original magnification, x400). Chromatin was stained with DAPI (blue), CD133, with Alexa Fluor ${ }^{\circledR} 568$ (red) and ABCG2 with fluorescein isothiocyanate (green). The images shown are representative of three independent experiments. ABCG2, breast cancer resistance protein; DAPI, 4',6-diamidino-2-phenylindole.

subcutaneous xenograft models, different numbers $\left(1 \times 10^{6}\right.$, $2 \times 10^{5}, 1 \times 10^{5}, 4 \times 10^{4}$ and $\left.1 \times 10^{4}\right)$ of freshly dissociated attached cells and sphere-derived cells were mixed with $100 \mu 1$ PBS and subcutaneously inoculated into the left and right flank of each BALB/c nude mouse to detect their tumorigenic capacity. The tumorigenicity was measured primarily by tumor size, tumor weight and latency, the latter determined as the duration between injection and the detection of palpable tumors. The primary tumor sizes were measured with a calliper on a weekly basis, and approximate tumor weights were determined using the following formula: $\mathrm{V}=1 / 2 \times \mathrm{a} \mathrm{x} \mathrm{b}^{2}$, where $\mathrm{b}$ is the smaller of the two perpendicular diameters and $\mathrm{V}$ is tumor volume. When the average tumor size reached 1,000-2,000 $\mathrm{mm}^{3}$, the animals were sacrificed by cervical dislocation. The grafts were then removed and fixed in formalin, and paraffin sections were prepared for hematoxylin and eosin (H\&E) staining and analyzed under a light microscope. All of the in vivo experimental procedures were approved by the Committee on the Ethical Use of Animals of the First Affiliated Hospital of Chongqing Medical University.

Statistical analysis. All experiments were performed in triplicate. The data are graphically represented as the mean \pm standard error of the mean. The values were compared with controls using either Student's t-test or two-way analysis of variance using Prism GraphPad 5.0 software (GraphPad Software, Inc.). $\mathrm{P}<0.05$ was considered to indicate a statistically significant difference.

\section{Results}

LC cells form floating spheres. The A549 attached cells were cultured in serum-free medium, as described above. Under ultra-low attached conditions, the cells grew into floating, tridimensional clusters, termed spheres. The spheres began to form on day 3 or 4 , and formation was more substantial on day 7 . Between days 9 and 12, the spheres had completely formed. By days 15-16, the spheres had become well-rounded structures, which were composed of abundant, cohesive cells. Fig. 1A shows the generation of a sphere from a single LC A549 cell. After 48 h of serum-driven culture, floating spheres were found to have adhered and migrated to the wall of the culture flasks, and gradually differentiated into adherent cells.

Intracellular localization of CD133 and ABCG2 in LC tumorospheres. To examine the subcellular localization of CD133 and ABCG2 in the sphere-forming cells, immunofluorescence staining of CD133 and ABCG2 was performed. Positive staining was observed, with CD133 and ABCG2 present primarily in the membranes of the spheres. Dual staining for CD133 and ABCG2 indicated that the two candidate CSC markers were colocalized in the spheres (Fig. 1B).

$L C$ spheres overexpress the CD133 and ABCG2 candidate CSC markers. To clarify the differential gene expression profiles between the spheres and the adherent A549 cells, RT-PCR and qPCR analyses were performed (Fig. 2A and B). As expected, cancer cells cultured in serum-free medium caused a shift in CSC markers, including marked upregulation of the following CSC markers: CD133, ABCG2, Oct-4, Sox-2 and Nanog. Compared with the attached cells, the flow cytometry data (Fig. 2C) showed significantly increased expression levels of CD133 $(0.35 \pm 0.06$, vs. $13.37 \pm 1.66 \%)$ and ABCG2 $(20.63 \pm 13.18$, vs. $73.72 \pm 11.57 \%)$ on the spheres.

LC tumorospheres harbor cells with CSC characteristics. The results of the flow cytometric analysis revealed the existence of distinct subpopulations with differential expression of CD133 and ABCG2 in the tumorospheres; a small subpopulation of $\mathrm{CD} 133^{+} / \mathrm{ABGC} 2^{+}$cells was identified in the A549 cells, whereas the primary cell population was negative for the two CSC markers. To investigate possible functional differences between these subpopulations, the CD133 ${ }^{+} / \mathrm{ABCG}^{+}$cells were subjected to FACS (Fig. 3A) and assessed using several functional assays. The CCK-8 assays revealed that the A549 spheres had markedly higher proliferation potential, as shown in Fig. 3B. Consistently, the 
A
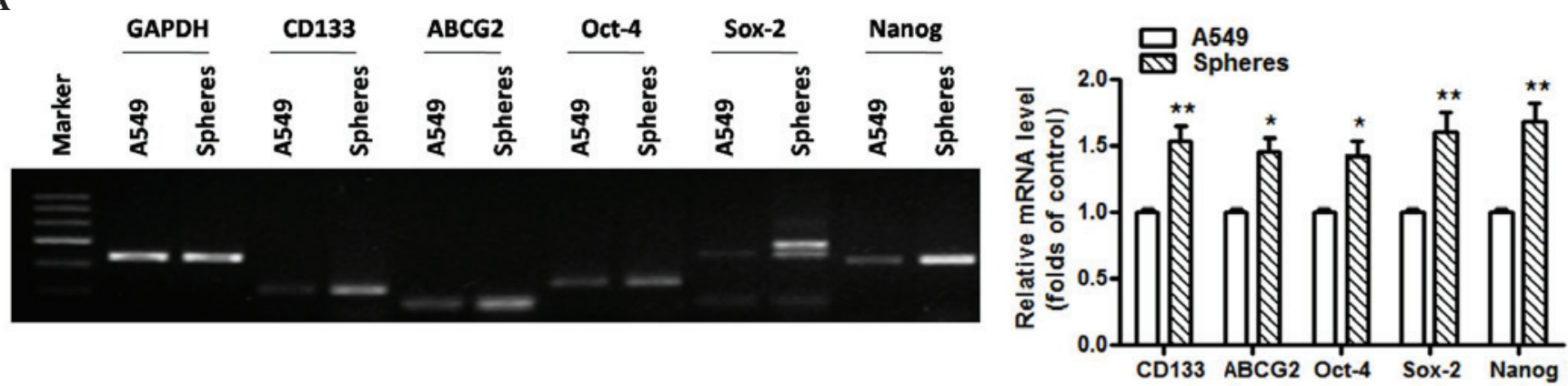

B
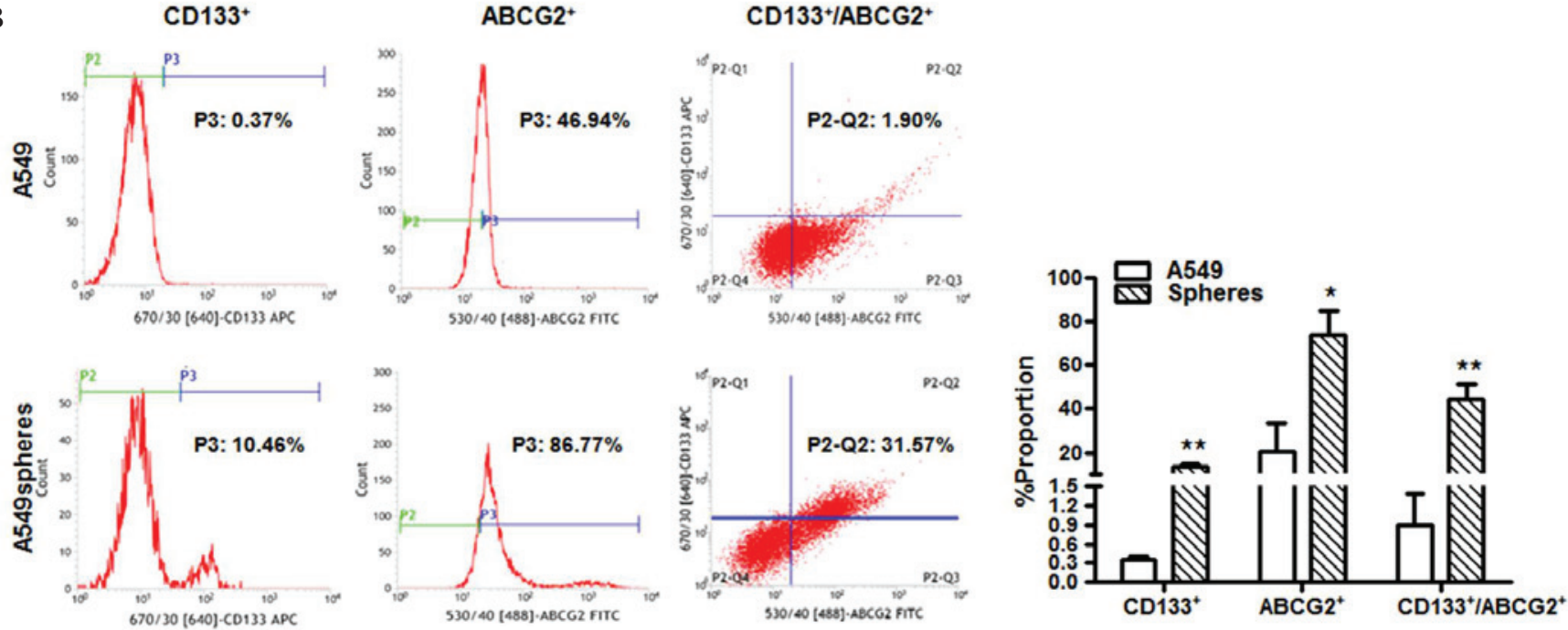

Figure 2. Lung cancer sphere-forming cells overexpress candidate CSC markers. (A) Reverse transcription-PCR and quantitative PCR analyses showed the upregulated expression levels of CD133, ABCG2, Oct-4, Sox-2 and Nanog in the A549 spheres ( $\mathrm{P}<0.05$ and $\left.{ }^{* *} \mathrm{P}<0.01\right)$. (B) Flow cytometric analysis demonstrated the increased expression of CD133 and ABCG2 cell surface antigens in the A549 lung tumorospheres ( $\mathrm{P}<0.05$ and $\left.{ }^{* *} \mathrm{P}<0.01\right)$. The results are presented as the mean \pm standard error of the mean. ABCG2, breast cancer resistance protein; PCR, polymerase chain reaction; APC, allophycocyanin; FITC, fluorescein isothiocyanate; Oct-4, octamer-binding transcription factor 4; Sox-2, sex-determining region Y-box 2.

results from the colony formation assay suggested that the

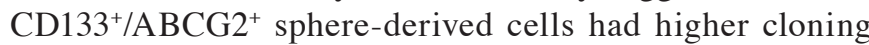
efficiency (3-4-fold; $368.569 \pm 70.96$, vs. $100 \pm 17.321)$ leading to the formation of larger colonies at earlier time points, with more cells having the ability to initiate a clone (Fig. 3C). In addition, the sphere-derived cells appeared to penetrate the Matrigel more readily (Fig. 3D), and the number of stained invasive cells was greater, compared with the attached cells (227.293 \pm 66.781 , vs. $100 \pm 8.66)$. Therefore, the LC tumorospheres were found to possess augmented proliferation and invasion abilities.

It is well known that there is a close association between cell cycle and cell function, including the ability of proliferation and differentiation, and chemosensitivity (22). In order to clarify the difference of cell cycle distribution between the A549 adherent cells and spheres, the cell cycle was analyzed using flow cytometry. The results (Fig. 3E) revealed that the A549 spheres formed in serum-free conditions exhibited the following cell cycle distribution: $76.69 \pm 4.31 \%$ in the G0/G1 phase, $14.02 \pm 2.65 \%$ in The $S$ phase and $9.29 \pm 2.70 \%$ in the G2/M phase. However, the A549 attached cells exhibited the following cell cycle distribution: $55.61 \pm 5.88 \%$ in the G0/G1 phase, $32.38 \pm 6.24 \%$ in the $\mathrm{S}$ phase and $12.01 \pm 2.47 \%$ in the G2/M phase. Therefore, the cell cycle of the spheres was arrested in the G0/G1 phase, with a corresponding reduction in the numbers of cells in the $\mathrm{S}$ and $\mathrm{G} 2 / \mathrm{M}$ phases. However, in response to the serum stimulus, the spheres acquired the following cell cycle phase distribution: $16.77 \pm 8.92 \%$ in the G0/G1 phase, $73.64 \pm 10.06 \%$ in the S phase and $9.59 \pm 5.04 \%$ in the $\mathrm{G} 2 / \mathrm{M}$ phase. This distribution indicated that the A549 spheres were steadily maintained in a quiescent state in serum-free conditions, which may partly contribute to the refractoriness to cancer therapy. However, the cell cycle progress was promoted with a significantly increased ratio of sub $S$ cells following treatment with serum, suggesting that the spheres had the capacity for unlimited self-renewal and extensive proliferation, and to generate differentiated progeny.

LC tumorospheres exhibit increased resistance to cisplatin. To examine whether LC tumorospheres possess the hypothesized chemoresistant phenotype of CSCs, the present study assessed the sensitivity of the sphere-forming cells and differentiated cells to cisplatin, which is commonly used in chemotherapy. The LC sphere-forming cells exhibited an increased $\mathrm{IC}_{50}$ value $(11.752 \pm 1.937$, vs. $1.485 \pm 0.121 \mu \mathrm{g} / \mathrm{ml})$, as shown in Fig. 4A. In addition, treatment with $5 \mu \mathrm{g} / \mathrm{ml}$ cisplatin did not affect the number or the size of the tumorospheres, suggesting enhanced chemoresistance of the sphere-forming cells (data not shown). The chemoresistance of tumor cells occurs, in part, due to the overexpression of ATP-binding cassette family 
A

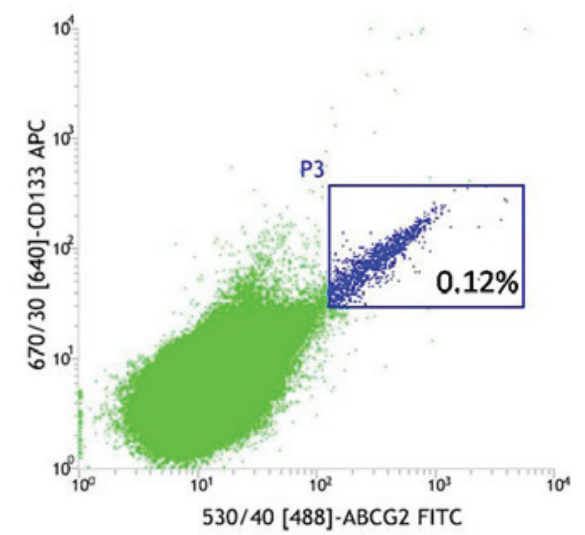

B

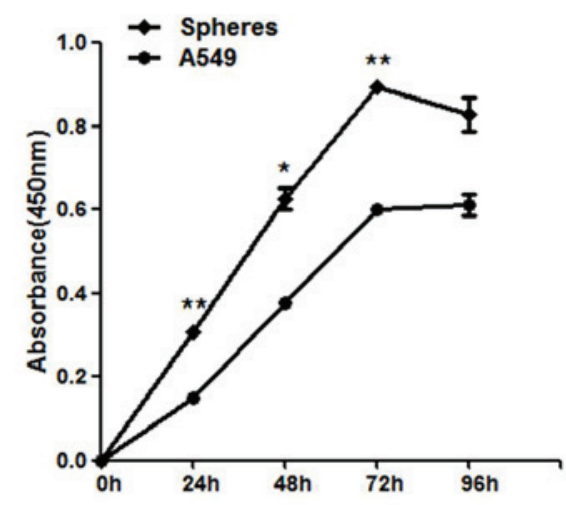

C

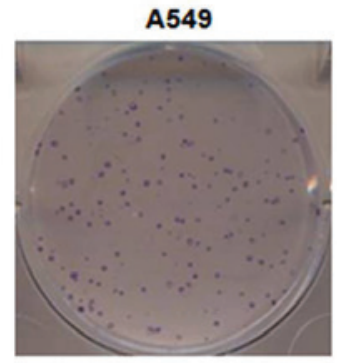

A549

D

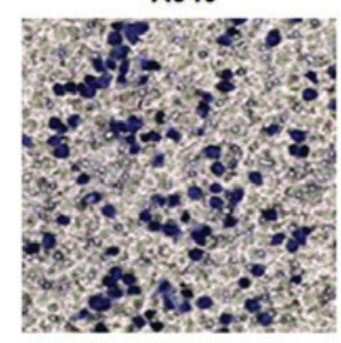

Spheres

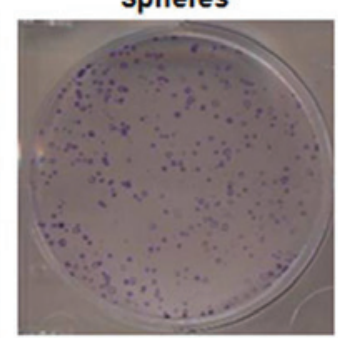

Spheres

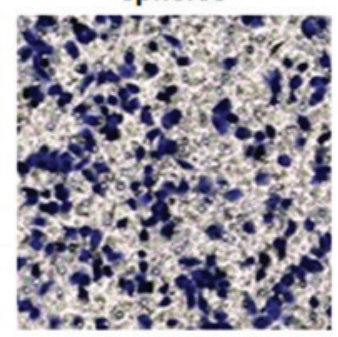

CD133+/ABCG2+
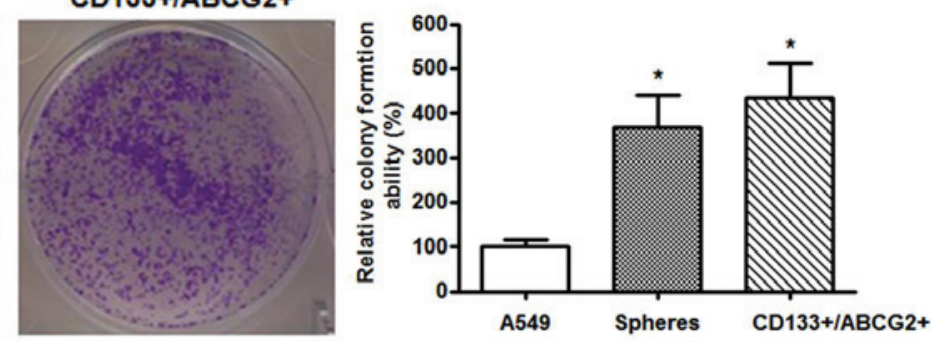

CD133+/ABCG2+
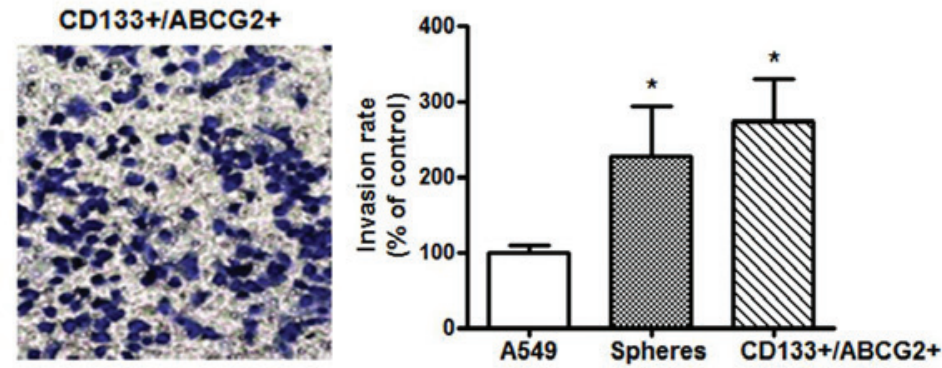

$\mathbf{E}$

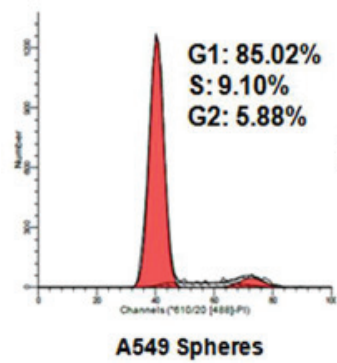

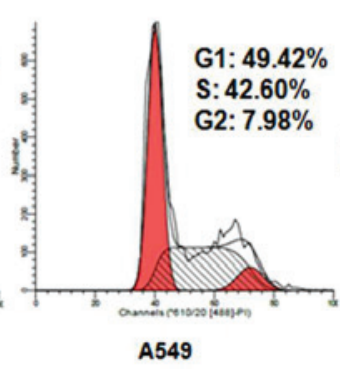

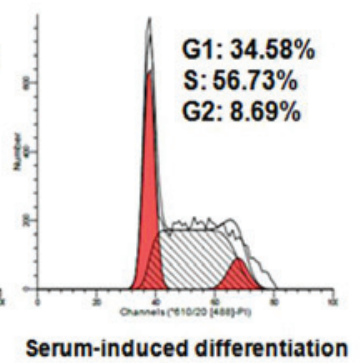

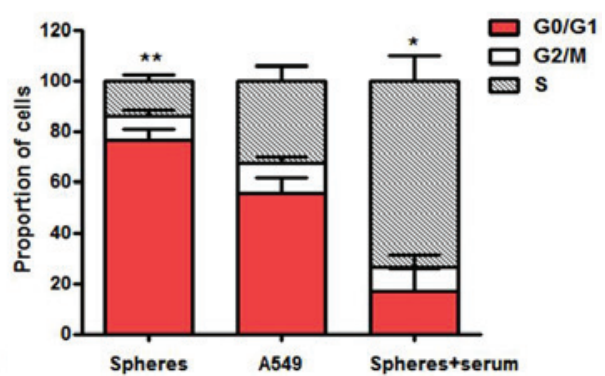

Figure 3. (A) A small population of $\mathrm{CD} 133^{+} / \mathrm{ABGC}^{+}$cells was separated using flow cytometry at a ratio of $0.12 \%$. (B) A Cell Counting Kit- 8 cell proliferation assay was used to compare A549 sphere-forming cells with the A549 control cells at each time point. (C) Representative colony formation assay and quantitative analysis of colony formation. The number of A549 colonies in the control was set to 100\%. (D) Matrigel invasion assay. Random fields were scanned (four fields per filter) for the presence of cells on the lower side of the membrane. Original magnification, $\mathrm{x} 400$. (E) Cell cycle was arrested at the G0/G1 phase in the sphere-derived cells. The results are presented as the mean \pm standard error of the mean and based on three independent experiments $\left({ }^{*} \mathrm{P}<0.05\right.$ and ${ }^{* *} \mathrm{P}<0.01$, vs. control). ABCG2, breast cancer resistance protein; APC, allophycocyanin; FITC, fluorescein isothiocyanate.

members, including ABCG2, P-glycoprotein and multidrug resistance protein $1(23,24)$. CD133 has also been reported to be partially associated to multidrug resistance. In the present study, the expression levels of CD133 and ABCG2 were further confirmed at the protein level by immunoblotting. The data indicated that the protein expression levels of CD133 and $\mathrm{ABCG} 2$ were substantially increased in tumorospheres, compared with adherent cells (Fig. 4B).
Tumorigenic potential of LC spheres. The cancer stem-like properties were further confirmed in the LC spheres through in vivo tumorigenicity experiments. The data showed that the A549 sphere-derived cells generated subcutaneous tumors with larger volumes in a shorter duration, compared with those from the attached cells. The tumor growth curves were compared for the two groups (Fig. 4C and D). In addition, as few as $4 \times 10^{4}$ cells from the A549 sphere-forming cells were 
A

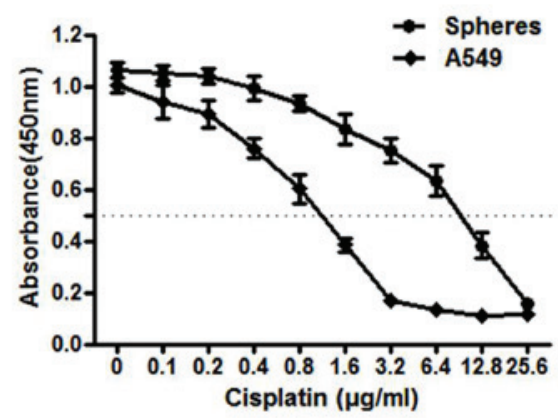

B

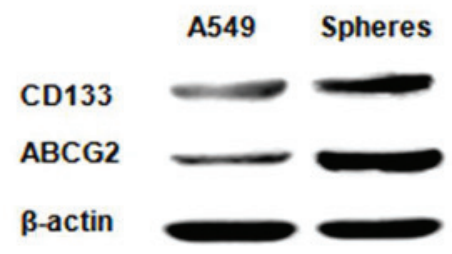

$\mathbf{C}$
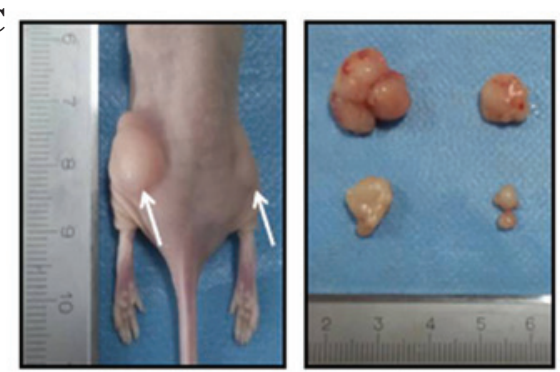
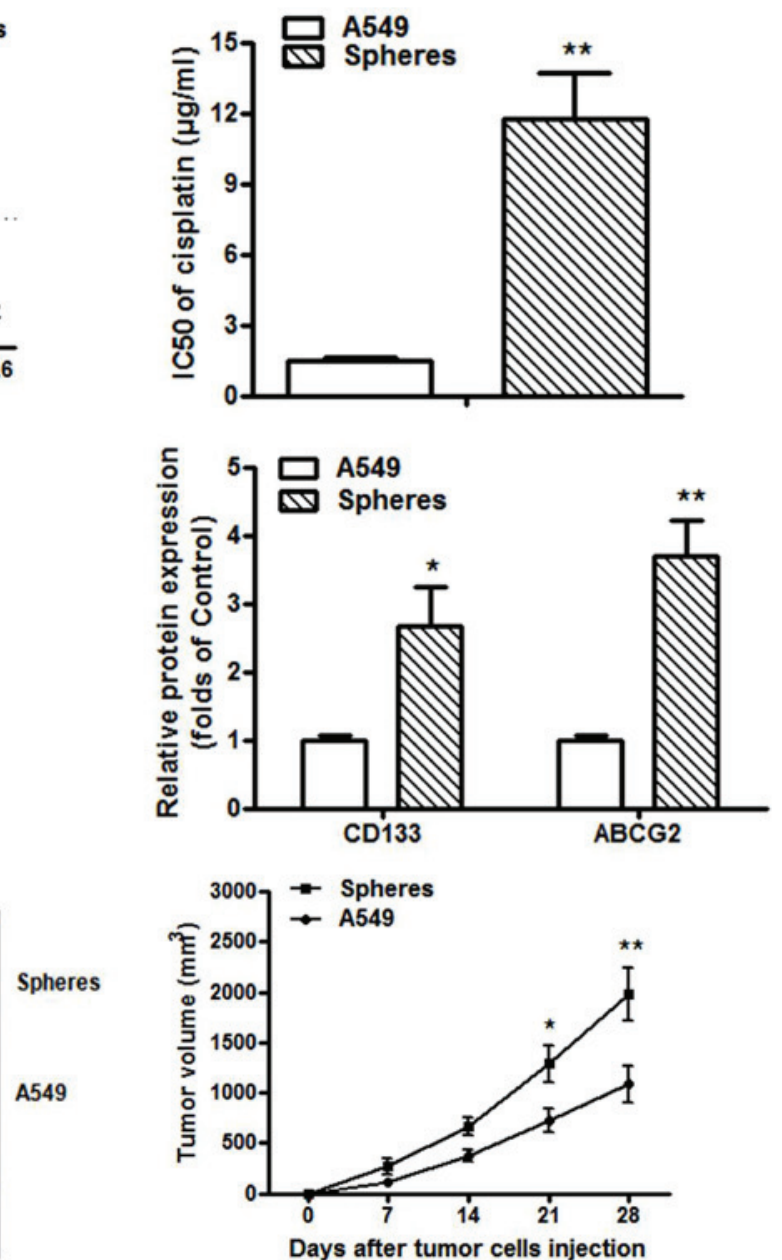

D

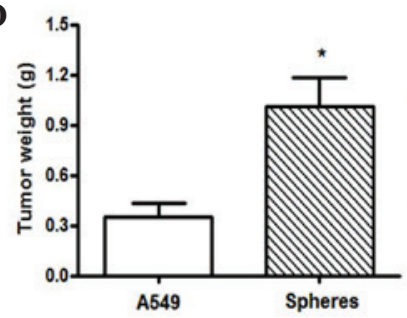

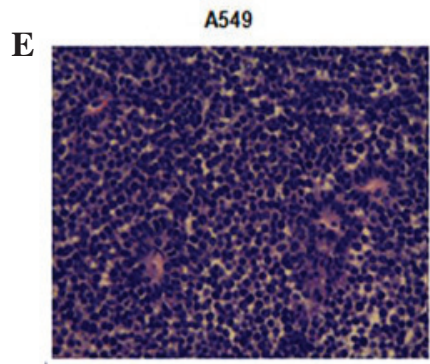

Figure 4. (A) Dose-response curves obtained from adherent and sphere-forming A549 cells following $48 \mathrm{~h}$ of treatment with different concentrations of cisplatin; the $\mathrm{IC}_{50}$ values were compared. (B) Expression levels of CD133 and ABCG2 were examined by immunoblotting. The experiments were performed three times in triplicate. ${ }^{*} \mathrm{P}<0.05$ and ${ }^{* *} \mathrm{P}<0.01$. Sphere-derived cells exhibited high tumorigenicity in vivo. (C) Representative example and nodules showing the xenograft tumors, which formed following subcutaneous injection with sphere-derived cells (left) and A549 attached cells (right) and a graph of tumor volume. (D) Tumor weights were measured in the two groups. The results are presented as the mean \pm standard error of the mean. ${ }^{*} \mathrm{P}<0.05$ and ${ }^{* *} \mathrm{P}<0.01$, vs. control. (E) Hematoxylin and eosin staining confirmed that the histological origin of the xenograft tumors was lung cancer (original magnification, x400). ABCG2, breast cancer resistance protein; $\mathrm{IC}_{50}$, half maximal inhibitory concentration.

able to form tumors at earlier time points when subcutaneously injected into nude mice, whereas $2 \times 10^{6}$ attached cells were required for the same effect; this value was 50 -fold higher than that for the sphere-forming cells. No differences in the overall health or conditions of vital organs were observed between the mice in the two groups (data not shown). The xenografts were confirmed as lung adenocarcinoma using H\&E staining (Fig. 4E), and the transplanted tumors derived from the A549 spheroid-forming cells were histologically similar to those from A549 adherent cells, predominantly containing differentiated cells. These data suggested that the LC sphere-derived cells showed an increased capacity for xenograft tumor formation in vivo.

\section{Discussion}

The CSC theory has received substantial attention in previous years. Determining whether this theory is applicable to LC may shed light on the initiation and metastasis formation of LC, and assist in developing specific therapies 
to target them, as current therapeutic strategies are developed to target the bulk of cancer cells and not the rarer CSCs. The first challenge lies in the specific isolation and identification of CSCs from LC.

The culture of CSCs as floating spheres was first described in brain tumors by Singh et al (25). In the following years, tumorospheres were continually developed from a wide range of solid tumors, including breast (26), ovarian $(12,27)$, pancreatic (28), oesophageal (29), liver (30), colonic (31), stomach (32) and prostate (33) cancer. To varying degrees, all these tumorospheres possess stem cell characteristics.

The present study provided a systematic evaluation of sphere-forming cells derived from the A549 LC cell line. The successful culture and isolation of lung tumorospheres in serum-free and anchorage-independent conditions were performed (Fig. 1A) and the stem-like properties of the tumorospheres were further investigated.

The expression of stemness genes is often used to identify CSCs (4). CD133, ABCG2 and other transcription factors, including OCT4, Sox 2 and Nanog were analyzed. They are essential for the maintenance of stem cells, and the overexpression of these genes was observed in sphere-derived cells compared with the attached cells. The upregulation in the expression levels of the stemness genes in sphere-forming cells was closely associated with the self-renewal potential, clonality, chemoresistance, invasion and metastasis, and the ability to form spheres and initiate xenografts. Of note, the CD133 ${ }^{+}$ sphere-derived cells colocalized with ABCG2, which may represent a subpopulation of putative CSCs. Therefore FACS was used in the present study to select $\mathrm{CD} 133^{+} / \mathrm{ABCG} 2^{+}$cells from the A549 spheres, which were only a small proportion of the tumorospheres, but exhibited higher cloning efficiency and more robust proliferation.

Chemoresistance remains the major cause of cancer associated-mortality and is also considered a hallmark of CSCs (23). To clarify whether sphere-derived cells possess chemoresistant properties, the present study analyzed the dose-response curves for the response to cisplatin of A549 adherent cells and sphere-derived cells. As expected, the sphere-derived cells exhibited increased resistance to treatment, with a higher percentage of survival, compared with the control cells. These data supported the effect of sphere-derived cells in chemoresistance, which may further reveal why conventional chemotherapy treatment fails to eradicate cancer cells, and leads to tumor metastasis and recurrence.

As chemotherapeutic drugs are generally more toxic towards rapidly proliferating cells, CSCs may resist the toxicity of cisplatin by remaining quiescent (4). To further examine whether their resistance is dependent on quiescence or the expression of drug-resistance proteins, including ABCG2, cell cycle and western blot analyses were performed. It was observed that the cell cycle of the A549 tumorospheres was arrested in the G0/G1 phase under serum-free conditions to maintain the quiescent and undifferentiated state. Following the withdrawal of growth factors and the addition of $10 \%$ FBS to the medium, floating sphere-derived cells were able to adhere and differentiate. The upregulation of drug-resistance proteins was further confirmed by immunoblotting. Therefore the overexpression of CD133 and ABCG2 at the translational level may be closely associated with the chemoresistance of A549 tumorospheres.
However, tumorospheres are not homogeneous structures enriched with only undifferentiated cells; they also contain more differentiated cells. Until now, no reports have accurately determined how many cells within tumorospheres are actually CSCs. The gold standard for evaluating the presence of CSCs is the transplantation of a small number of cells into an immunocompromised mouse and evaluating of the capacity of tumorigenesis in vivo (34). In the present study, A549 attached cells and a 50-fold lower number of cells from A549 spheres were harvested and used to generate subcutaneous xenograft models. The sphere-derived cells exhibited the capacity to generate xenografts with larger volumes and faster growth rates, compared with the attached cells. These results demonstrated that the sphere-forming cells predominantly represented CSCs, which possessed potent proliferation capacity and tumorigenicity.

In conclusion, the present study demonstrated that non-adherent tumorospheres of an LC cell line cultured in a defined serum-free medium exhibited the characteristics of multipotent stem cells. The genetic composition of the sphere-derived cells, in terms of the co-expression of CD133 and $\mathrm{ABCG} 2$, may represent the determining factor for the stem-like features and is likely to be valuable for future gene and stem cell therapy for LC. However, further investigations are required to elucidate the underlying mechanisms of lung CSCs in detail.

\section{Acknowledgements}

This study was supported by the National Natural Science Foundation of China (grant no. 81302018) and the Oncology National Clinical Key Specialty Construction Project [The Medical Letter of National Health and Family Planning Commission Office (2013) 544].

\section{References}

1. Dela Cruz CS, Tanoue LT and Matthay RA: Lung cancer: Epidemiology, etiology, and prevention. Clin Chest Med 32: 605-644, 2011.

2. Siegel RL, Miller KD and Jemal A: Cancer statistics, 2015. CA Cancer J Clin 65: 5-29, 2015.

3. Reya T, Morrison SJ, Clarke MF and Weissman IL: Stem cells, cancer, and cancer stem cells. Nature 414: 105-111, 2001.

4. Tirino V, Desiderio V, Paino F, De Rosa A, Papaccio F, La Noce M, Laino L, De Francesco F and Papaccio G: Cancer stem cells in solid tumors: An overview and new approaches for their isolation and characterization. FASEB J 27: 13-24, 2013.

5. Weiswald LB, Bellet D and Dangles-Marie V: Spherical cancer models in tumor biology. Neoplasia 17: 1-15, 2015.

6. Yamamuro S, Okamoto Y, Sano E, Ochiai Y, Ogino A, Ohta T, Hara H, Ueda T, Nakayama T, Yoshino A and Katayama Y: Characterization of glioma stem-like cells from human glioblastomas. Int J Oncol 47: 91-96, 2015.

7. Iacopino F, Angelucci C, Piacentini R, Biamonte F, Mangiola A, Maira G, Grassi C and Sica G: Isolation of cancer stem cells from three human glioblastoma cell lines: Characterization of two selected clones. PLoS One 9: e105166, 2014.

8. Zakaria N, Yusoff NM, Zakaria Z, Lim MN, Baharuddin PJ Fakiruddin KS and Yahaya B: Human non-small cell lung cancer expresses putative cancer stem cell markers and exhibits the transcriptomic profile of multipotent cells. BMC Cancer 15: 84, 2015.

9. Alamgeer M, Peacock CD, Matsui W, Ganju V and Watkins DN: Cancer stem cells in lung cancer: Evidence and controversies. Respirology 18: 757-764, 2013. 
10. Eramo A, Lotti F, Sette G, Pilozzi E, Biffoni M, Di Virgilio A, Conticello C, Ruco L, Peschle C and De Maria R: Identification and expansion of the tumorigenic lung cancer stem cell population. Cell Death Differ 15: 504-514, 2008.

11. Grosse-Gehling P, Fargeas CA, Dittfeld C, Garbe Y, Alison MR, Corbeil D and Kunz-Schughart LA: CD133 as a biomarker for putative cancer stem cells in solid tumors: Limitations, problems and challenges. J Pathol 229: 355-378, 2013.

12. Cioffi M, D'Alterio C, Camerlingo R, Tirino V, Consales C, Riccio A, Ieranò C, Cecere SC, Losito NS, Greggi S, et al: Identification of a distinct population of CD133(+)CXCR4(+) cancer stem cells in ovarian cancer. Sci Rep 5: 10357, 2015.

13. Kashihara H, Shimada M, Kurita N, Iwata T, Sato H, Kozo Yoshikawa, Higashijima J, Chikakiyo M, Nishi M and Matsumoto N: CD133 expression is correlated with poor prognosis in colorectal cancer. Hepatogastroenterology 61: 1563-1567, 2014.

14. Nomura A, Banerjee S, Chugh R, Dudeja V, Yamamoto M, Vickers SM and Saluja AK: CD133 initiates tumors, induces epithelial-mesenchymal transition and increases metastasis in pancreatic cancer. Oncotarget 6: 8313-8322, 2015.

15. Nosrati A, Naghshvar F and Khanari S: Cancer stem cell markers CD44, CD133 in primary gastric adenocarcinoma. Int J Mol Cell Med 3: 279-286, 2014

16. Yin S, Li J, Hu C, Chen X, Yao M, Yan M, Jiang G, Ge C, Xie H, Wan D, et al: CD133 positive hepatocellular carcinoma cells possess high capacity for tumorigenicity. Int J Cancer 120: 1444-1450, 2007

17. Feng BH, Liu AG, Gu WG, Deng L, Cheng XG, Tong TJ and Zhang HZ: CD133+ subpopulation of the HT1080 human fibrosarcoma cell line exhibits cancer stem-like characteristics. Oncol Rep 30: 815-823, 2013.

18. Nakanishi T and Ross DD: Breast cancer resistance protein (BCRP/ABCG2): Its role in multidrug resistance and regulation of its gene expression. Chin J Cancer 31: 73-99, 2012.

19. Robey RW, To KK, Polgar O, Dohse M, Fetsch P, Dean M and Bates SE: ABCG2: A perspective. Adv Drug Deliv Rev 61: 3-13, 2009.

20. Sicchieri RD, da Silveira WA, Mandarano LR, Gonçalves de Oliveira TM, Carrara HH, Muglia VF, de Andrade JM and Tiezzi DG: ABCG2 is a potential marker of tumor-initiating cells in breast cancer. Tumor Biol 36: 9233-9243, 2015.

21. Ballester M1, Castelló A, Ibáñez E, Sánchez A and Folch JM: Real-time quantitative PCR-based system for determining transgene copy number in transgenic animals. Biotechniques 37: $610-613,2004$
22. Williams GH and Stoeber K: The cell cycle and cancer. J Pathol 226: 352-364, 2012.

23. Abdullah LN and Chow EK: Mechanisms of chemoresistance in cancer stem cells. Clin Transl Med 2: 3, 2013

24. Dean M, Fojo T and Bates S. Tumour stem cells and drug resistance. Nat Rev Cancer 5: 275-284, 2005.

25. Singh SK, Clarke ID, Terasaki M, Bonn VE, Hawkins C, Squire J and Dirks PB: Identification of a cancer stem cell in human brain tumors. Cancer Res 63: 5821-5828, 2003.

26. Piscitelli E, Cocola C, Thaden FR, Pelucchi P, Gray B, Bertalot G, Albertini A, Reinbold R and Zucchi I: Culture and characterization of mammary cancer stem cells in mammospheres. Methods Mol Biol 1235: 243-262, 2015.

27. House CD, Hernandez L and Annunziata CM: In vitro enrichment of ovarian cancer tumor-initiating cells. J Vis Exp: 2015.

28. Fredebohm J, Boettcher M, Eisen C, Gaida MM, Heller A, Keleg S, Tost J, Greulich-Bode KM, Hotz-Wagenblatt A, Lathrop $\mathrm{M}$, et al: Establishment and characterization of a highly tumorigenic and cancer stem cell enriched pancreatic cancer cell line as a well defined model system. PLoS One 7: e48503, 2012.

29. Fujiwara D, Kato K, Nohara S, Iwanuma Y and Kajiyama Y: The usefulness of three-dimensional cell culture in induction of cancer stem cells from esophageal squamous cell carcinoma cell lines. Biochem Biophys Res Commun 434: 773-778, 2013.

30. Zhu L, Zhang W, Wang J and Liu R: Evidence of CD90+CXCR4+ cells as circulating tumor stem cells in hepatocellular carcinoma. Tumor Biol 36: 5353-5360, 2015.

31. Saha A, Shree Padhi S, Roy S and Banerjee B: HCT116 colonospheres shows elevated expression of hTERT and $\beta$-catenin protein-a short report. J Stem Cells 9: 243-251, 2014.

32. Liu J, Ma L, Xu J, Liu C, Zhang J, Liu J, Chen R and Zhou Y: Sphere-forming body-forming cells in the human gastric cancer cell line MKN-45 possess cancer stem cell properties. Int J Oncol 42: 453-459, 2013.

33. Castillo V, Valenzuela R, Huidobro C, Contreras HR and Castellon EA: Functional characteristics of cancer stem cells and their role in drug resistance of prostate cancer. Int J Oncol 45: 985-994, 2014

34. Clarke MF, Dick JE, Dirks PB, Eaves CJ, Jamieson CH, Jones DL, Visvader J, Weissman IL and Wahl GM: Cancer stem cells-perspectives on current status and future directions: AACR Workshop on cancer stem cells. Cancer Res 66: 9339-9344, 2006. 